\title{
Estimating genomic instability mediated by Alu retroelements in breast cancer
}

Ana Cristina Fazza ${ }^{1}$, Flavia Cal Sabino ${ }^{1}$, Nathalia de Setta ${ }^{1}$, Newton Antonio Bordin Jr. ${ }^{2}$, Eloiza Helena Tajara da Silva ${ }^{3,4}$ and Claudia Marcia Aparecida Carareto ${ }^{1}$

${ }^{1}$ Departamento de Biologia, Instituto de Biociências, Letras e Ciências Exatas, Universidade Estadual Paulista “Júlio De Mesquita Filho", São José Rio Preto, SP, Brazil.

${ }^{2}$ Departamento de Ginecologia e Obstetrícia, Faculdade de Medicina, São José do Rio Preto, SP, Brazil.

${ }^{3}$ Departamento de Biologia Molecular, Faculdade de Medicina, São José do Rio Preto, SP, Brazil.

${ }^{4}$ Departamento de Genética e Biologia Evolucionária, Instituto de Biociências, Universidade de São Paulo, São Paulo, SP, Brazil.

\begin{abstract}
Alu-PCR is a relatively simple technique that can be used to investigate genomic instability in cancer. This technique allows identification of the loss, gain or amplification of gene sequences based on the analysis of segments between two Alu elements coupled with quantitative and qualitative analyses of the profiles obtained from tumor samples, surgical margins and blood. In this work, we used Alu-PCR to identify gene alterations in ten patients with invasive ductal breast cancer. Several deletions and insertions were identified, indicating genomic instability in the tumor and adjacent normal tissue. Although not associated with specific genes, the alterations, which involved chromosomal bands 1p36.23, 1q41, 11q14.3, 13q14.2, occurred in areas of well-known genomic instability in breast and other types of cancer. These results indicate the potential usefulness of Alu-PCR in identifying altered gene sequences in breast cancer. However, caution is required in its application since the Alu primer can produce non-specific amplification.
\end{abstract}

Key words: Alu-PCR, breast cancer, gene insertions, gene deletions, invasive ductal carcinoma, recombination.

Received: February 18, 2008; Accepted: August 11, 2008.

\section{Introduction}

Molecular genetic and cytogenetic analyses of breast cancer samples suggest that the development of this type of cancer involves the clustering of several, mainly structural, genetic alterations (Devilee and Cornelisse, 1994; ElAshry and Lippmann, 1994; Beckmann et al., 1997). Point mutations, such as small deletions and insertions, are the most widely described mutations, although genomic rearrangements are also very common (Montagna et al., 2003; Belogianni et al., 2004; Agata et al., 2005). Chromosomal deletions and loss of heterozygosity $(\mathrm{LOH})$ may indicate the inactivation of tumor suppressor genes in the affected region (Kenemans et al., 2004).

One of the mechanisms proposed to explain the origin of deletions and insertions is based on the dispersion dynamics of transposable elements in the genome. According to Presneau et al. (1998), abortive integration of a transposon can be simultaneously responsible for a deletion and an insertion. The insertion of a transposon may damage DNA by interrupting the gene, but when unequal homolog recombination occurs several genes can be affected, with

Send correspondence to Claudia Marcia Aparecida Carareto. Departamento de Biologia, Instituto de Biociências, Letras e Ciências Exatas, Universidade Estadual Paulista "Júlio De Mesquita Filho", 15054-000 São José Rio Preto, SP, Brazil. E-mail: carareto@ibilce.unesp.br. unpredictable consequences to the phenotype. Indeed, there is strong evidence of a relationship between transposable elements and human genetic diseases. For example, insertion of Alu elements appears to be involved in the etiology of $0.1-0.3 \%$ of human genetic diseases, including TaySachs disease, Duchenne muscular dystrophy, complement deficiency, and breast, ovary and colorectal cancer (Batzer and Deininger, 2002; Chen et al., 2005).

A relatively simple technique that has been used to investigate genomic instability in cancer is $A l u$-PCR (Tsongalis et al., 1993; Furmaga et al., 2003, 2004) that is based on the large number of copies of the Alu retroelement in the human genome. Alu elements are sequences of $\sim 300 \mathrm{nu}-$ cleotides (Cordaux et al., 2006) known as SINEs (short interspersed nuclear elements), of which there are $\sim 500,000$ copies (Deininger and Batzer, 1999; Batzer and Deininger, 2002 ) that account for $10 \%$ of the human genome $(\mathrm{Ng}$ and Xue, 2006). Deletions or insertions between two elements are easily detected by PCR (Strout et al., 1998; Suminaga et al., 2000; Rowold and Herrera, 2000; Stenger et al., 2001; Weichenrieder et al., 2001). Since Alu elements can be inserted in opposite directions in a DNA sequence, it is possible to use only one primer in the PCR reaction to detect genetic alterations in cancer cells (Furmaga et al., 2003). Alu-PCR does not search for a specific locus but yields a profile of bands of genomic DNA that may differ 
between tumor and normal adjacent (control) tissues of the same patient. The gain or loss of genomic material may involve large or small gene sequences associated with $\mathrm{LOH}$ and/or gene amplification.

According to Fumarga et al. (2003, 2004), Alu-PCR is a very sensitive technique that has the advantage of being able to detect novel genomic alterations without the need for prior knowledge of these sequences. Alu-PCR has been used to identify the genetic changes potentially involved in lung carcinoma metastasis (Furmaga et al., 2003) and to distinguish typical pulmonary carcinoids from classic midgut carcinoids, which are histologically similar (Furmaga et al., 2004). However, there is no information about the sequences of the altered bands that allows identifying the segments involved in the genetic gains or losses.

The aim of this study was to investigate the genomic instability of sporadic invasive ductal breast cancer by using $A l u$-PCR as an alternative approach to other methods commonly used to obtain comparative fingerprints of cancer and normal tissues, e.g., AP-PCR (Peinado et al., 1992), MS-AP-PCR (Gonzalgo et al., 1997) and Inter-SSR-PCR (Basik et al., 1997). Additionally, we sequenced the fragments involved in the gains or losses in order to identify their sequences and compared them with the human genome database.

\section{Material and Methods}

\section{Samples}

Genomic DNA was extracted from tumor and apparently normal tissues, surgical margins and blood of ten patients (50-69 years old) who underwent surgery for removal of invasive ductal breast carcinoma with grade II or III tumors. The samples were collected and the tumor grade was classified macroscopically by medical professionals of the Gynecological Oncology and Mastology Unit of the Department of Gynecology and Obstetrics, the Plastic Surgery Service of the Department of Surgery, and the Pathological Anatomy Service of the Department of Pathology and Forensic Medicine of the São José do Rio Preto School of Medicine. The material was donated after written informed consent from all participants and its use in this project was approved by the Ethics Committee at UNESP in São José do Rio Preto and by the National Committee for Ethics in Research (CONEP, registration no. 10811).

\section{Genomic DNA extraction}

Genomic DNA was extracted from fresh solid tissue by using the DNA extraction protocol described by Sambrook et al. (1989).

\section{Alu-PCR}

Hot-start PCR was done with $150 \mathrm{ng}$ of genomic DNA in a reaction with a final volume of $25 \mu \mathrm{L}$ containing $1.25 \mathrm{U}$ of TaqBead hot-start polymerase (Promega),
$200 \mu \mathrm{M}$ of each dNTP, $1 \mathrm{X}$ PCR buffer, $1.5 \mathrm{mM} \mathrm{MgCl}_{2}$ and $100 \mathrm{ng}$ of Alu initiator (5'-GGCAGACTCCATCTCAAA3 ') that anneals at the 3' end of the Alu element, immediately before the poly-A tail. The cycling parameters were: initial denaturation at $94{ }^{\circ} \mathrm{C}$ for $3 \mathrm{~min}$, followed by $40 \mathrm{cy}$ cles of denaturation at $94{ }^{\circ} \mathrm{C}$ for $2 \mathrm{~min}$, annealing at $55^{\circ} \mathrm{C}$ for $2 \mathrm{~min}$ and extension at $72^{\circ} \mathrm{C}$ for $3 \mathrm{~min}$. The final extension was at $72{ }^{\circ} \mathrm{C}$ for $10 \mathrm{~min}$. The amplification products were separated by electrophoresis in $7.5 \%$ polyacrylamide gels and stained with silver nitrate (Caetano-Anollés and Bassam, 1993). Initially, the gels were run at a constant power of $300 \mathrm{~V}$ for $30 \mathrm{~min}$ followed by $4 \mathrm{~h}$ at a constant power of $100 \mathrm{~V}$ at room temperature. The gels were fixed using a standard procedure and dried on cellophane and $20 \%$ glycerol, as described by Ceron et al. (1992).

\section{Selection of candidate bands and extraction}

The bands representing possible insertions, deletions and amplifications were extracted from the dried gels and eluted overnight at $37^{\circ} \mathrm{C}$ in elution buffer. The eluted material was then centrifuged and the DNA was precipitated, dehydrated and eluted in $10 \mu \mathrm{L}$ of elution buffer followed by storage at $-20^{\circ} \mathrm{C}$ for subsequent cloning and sequencing.

Quantitative (gain or loss of a specific band) and qualitative (change in band intensity) analyses of the Alu profile were done by comparing the profiles of 100-700 bp fragments obtained with this technique since bands in this size range provided better staining and visualization. The bands were visualized with a UV lightbox since this allowed the detection of weakly stained bands that were difficult to see in digitalized images.

\section{Cloning and sequencing}

Fragments extracted from the polyacrylamide gels were amplified under the same conditions as the Alu-PCR. The products were separated on $1 \%$ agarose gels, from which they were subsequently extracted, purified and cloned. Two colonies in which the presence of the plasmid with an insert was confirmed were selected and the plasmids were extracted using the alkaline lysis "miniprep" method (FlexiPrep kit, Amersham), according to the manufacturer's instructions. Sequencing was done in an ABI 377 sequencer and sequence consensus was determined with the BioEdit Sequence Alignment Editor program (Hall, 1999). Sequence identification and chromosomal localization were determined by searching the human genome database with the basic local alignment tools BLAST and BLAT.

\section{Results}

Differences in the electrophoretic band profile were observed in 9 out of the 10 cases studied. The total number of quantitative and qualitative alterations observed was $3.30 \pm 2.98$ per patient (mean \pm SD Table 1 ), and the most 
frequently observed alteration was the loss of bands in tumor tissue ( $1.00 \pm 1.05$ alterations per patient). Two figures are provided to illustrate the results obtained. Figure 1 shows the electrophoretic profiles of the three replicates of tumor, surgical margin and blood DNA samples from patient n. 2 and confirms the reproducibility of the results. This figure also shows that blood contained a band that was absent for the surgical margin and tumor samples. Figure 2 shows the electrophoretic profiles of the tumor, surgical margin and blood DNA of patient no. 5. In this case, the tumor tissue showed two deletions, one of $\sim 500 \mathrm{bp}$ (for which the corresponding band in blood was sequenced) and another of $\sim 600$ bp that was only weakly visible in the digitalized image.

Five bands from different cases were selected for cloning and sequencing. Table 2 summarizes the tissues (tumor, surgical margin or blood) that were altered in five patients and shows the band that was selected for sequenc-

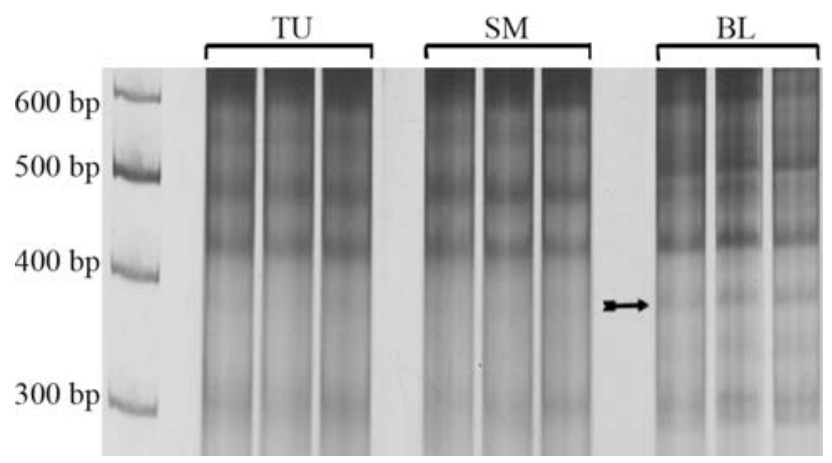

Figure 1 - Electrophoretic profiles of three replicates of tumor (TU), surgical margin (SM) and blood (BL) DNA samples from patient no. 2 showing the reproducibility of the $A l u$-PCR profile in breast cancer. The arrow indicates a band present in the blood sample that is less visible in the surgical margin and absent in tumor tissue. ing, the type of genetic alteration (gain or loss of a sequence), the band size, the gene location of each altered sequence and the identity of each clone with a sequence in the human genome. The chromosomal location of these sequences is shown in Figure 3. All of the sequences had a transposable element at at least one extremity or internally, within the sequence. The only case with Alu sequences at both extremities, as shown by $A l u$-PCR, was patient 10: the sequence had an AluSg1 sequence at the 5' end and an AluSg sequence at the 3' end. In patient no. 2, the sequence consisted of an L1PA14 element of the LINE superfamily, followed by an AluSg sequence at the 3' end. In patient no. 5 , the sequence that was amplified belonged to an intronic region of the KCNK2 gene that harbored three transposable elements, L1ME1, AluJo and AluSc, of which AluJo was possibly a complete element because of its $294 \mathrm{bp}$ size. Patients 3 and 9 had exactly the same altered region, with an Alu element at the 3' end and no other transposable ele-

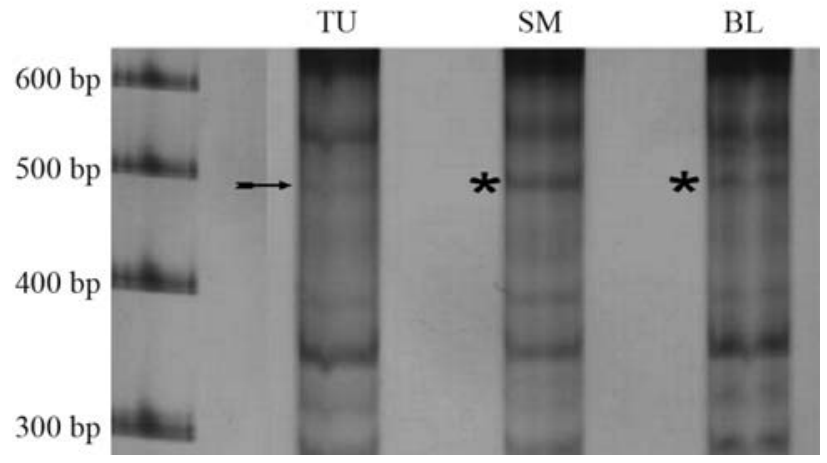

Figure 2 - Electrophoretic profiles of tumor (TU), surgical margin (SM) and blood (BL) DNA samples from patient no. 5. Note the presence of two deletions in the tumor tissue, one of $\sim 500 \mathrm{bp}$ (sequenced from the corresponding band extracted from the blood sample, indicated by the asterisk) and another of $\sim 600 \mathrm{bp}$ (this band was fainter in the digitalized image).

Table 1 - Quantitative and qualitative changes observed in the Alu profile.

\begin{tabular}{|c|c|c|c|c|c|c|c|c|c|c|}
\hline \multirow{3}{*}{ Sample } & \multicolumn{6}{|c|}{ Quantitative } & \multicolumn{3}{|c|}{ Qualitative } & \multirow[t]{3}{*}{ Total } \\
\hline & \multicolumn{3}{|c|}{ Band gain } & \multicolumn{3}{|c|}{ Band loss } & \multirow[b]{2}{*}{$\mathrm{TU}$} & \multirow[b]{2}{*}{ SM } & \multirow[b]{2}{*}{$\mathrm{BL}$} & \\
\hline & $\mathrm{TU}$ & SM & $\mathrm{BL}$ & $\mathrm{TU}$ & SM & $\mathrm{BL}$ & & & & \\
\hline Patient 1 & 1 & 1 & 0 & 0 & 0 & 0 & 0 & 0 & 0 & 2 \\
\hline Patient 2 & 0 & 0 & 0 & 3 & 2 & 0 & 0 & 0 & 0 & 5 \\
\hline Patient 3 & 3 & 3 & 0 & 2 & 0 & 0 & 1 & 0 & 0 & 9 \\
\hline Patient 4 & 0 & 1 & 0 & 1 & 1 & 0 & 2 & 1 & 0 & 6 \\
\hline Patient 5 & 1 & 0 & 0 & 2 & 2 & 0 & 1 & 0 & 0 & 6 \\
\hline Patient 6 & 0 & 0 & 0 & 1 & 0 & 0 & 0 & 0 & 0 & 1 \\
\hline Patient 7 & 0 & 0 & 0 & 0 & 0 & 0 & 0 & 0 & 0 & 0 \\
\hline Patient 8 & 0 & 0 & 0 & 1 & 0 & 0 & 0 & 0 & 0 & 1 \\
\hline Patient 9 & 0 & 0 & 0 & 0 & 0 & 0 & 1 & 0 & 0 & 1 \\
\hline Patient 10 & 0 & 0 & 0 & 0 & 0 & 0 & 1 & 1 & 0 & 2 \\
\hline Mean \pm SD & $0.50 \pm 0.97$ & $0.50 \pm 0.97$ & 0 & $1.00 \pm 1.05$ & $0.50 \pm 0.85$ & 0 & $0.60 \pm 0.69$ & $0.20 \pm 0.42$ & 0 & $3.30 \pm 2.98$ \\
\hline
\end{tabular}

$\mathrm{BL}$ - blood, SM - surgical margin, TU - tumor. 
ments at the 5 ' end. Although they shared the same altered region, patient 3 presented a sequence gain and patient $9 \mathrm{a}$ sequence loss.

Figure 4 shows the non-specific alignments between the Alu primer and the LINE elements found in the sequenced fragment of patients 2 (L1PA14) and 5 (L1ME1) and in the flanking region without an $A l u$ element in patients 3 and 9 . As can be seen, 10-13 of the 18 nucleotides of the Alu primer occurred in the 3' end of the L1PA14 and $L 1 M E 1$ elements or in the intergenic flanking region. The high similarity (55\%-72\%) between the sequences of these regions and the $A l u$ primer apparently accounted for the non-specific amplifications.

\section{Discussion}

Genomic instability accompanies the progression of neoplasia and probably predisposes the individual to additional genetic alterations that confer proliferative advantages to the cells. The sequence between two Alu elements may be more susceptible to deletions and unequal recom-

Table 2 - Sequencing results for the candidate bands.

\begin{tabular}{lcccccc}
\hline Patient & Altered tissue & Band alteration & Tissue analyzed & Band size & Genomic localization (position) & Identity (\%) \\
\hline 2 & TU and SM & Loss & BL & $300-400 \mathrm{bp}$ & $11 \mathrm{q} 14.3(89867448-89868025)$ & 98.7 \\
2 & TU and SM & Loss & BL & $300-400 \mathrm{bp}$ & $11 \mathrm{q} 14.3(89867448-89868009)$ & 99.3 \\
\hline 3 & TU and SM & Gain & TU and SM & $400-500 \mathrm{bp}$ & $1 \mathrm{p} 36.23(8828760-8829352)$ & 96.8 \\
3 & TU and SM & Gain & TU and SM & $400-500 \mathrm{bp}$ & $1 \mathrm{p} 36.23(8828760-8829328)$ & 98.0 \\
\hline 5 & TU & Loss & BL and SM & $500 \mathrm{bp}$ & $1 \mathrm{q} 41(213251146-213251604)$ & 99.8 \\
5 & TU & Loss & BL and SM & $500 \mathrm{bp}$ & $1 \mathrm{q} 41(213251146-213251604)$ & 99.8 \\
\hline 9 & TU and SM & Loss & BL & $300-400 \mathrm{bp}$ & $1 \mathrm{p} 36.23(8828760-8829350)$ & 98.6 \\
9 & TU and SM & Loss & BL & $300-400 \mathrm{bp}$ & $1 \mathrm{p} 36.23(8828760-8829354)$ & 98.7 \\
\hline 10 & TU and SM & Gain & TU and SM & $500 \mathrm{bp}$ & $13 \mathrm{q} 14.2(47667917-47668511)$ & 98.9 \\
10 & TU and SM & Gain & TU and SM & $500 \mathrm{bp}$ & $13 \mathrm{q} 14.2(47667917-47668496)$ & 99.1 \\
\hline
\end{tabular}

$\mathrm{BL}$ - blood, SM - surgical margin, TU - tumor.
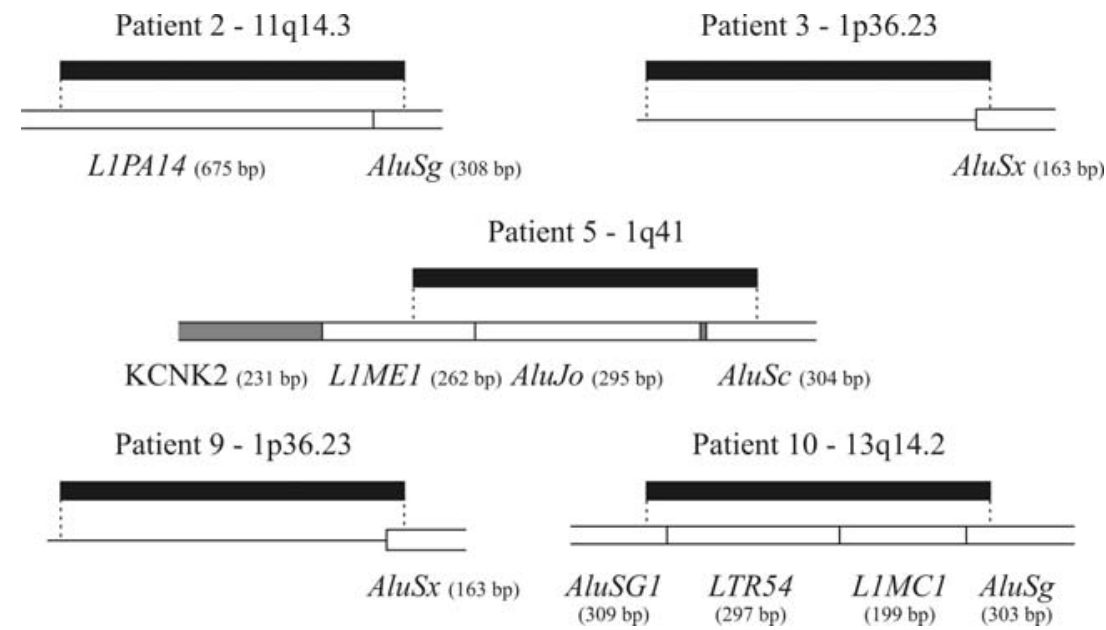

Figure 3 - Schematic representation of the chromosomal position of each sequence extracted from the gels. The black boxes indicate the sequences that were analyzed, the empty boxes below each sequence represent transposable elements, and the gray boxes represent exons of the KCNK2 gene.

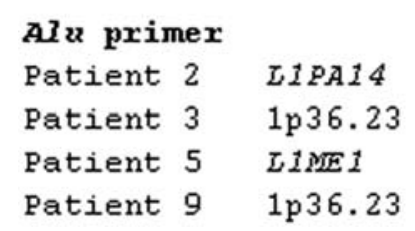

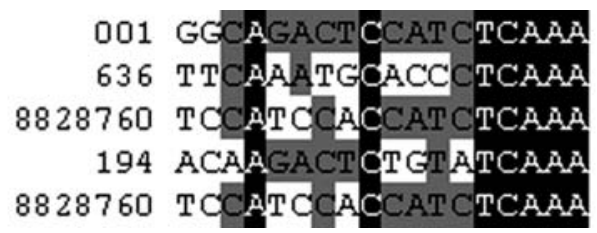

018

653

8828777

211

8828777

Figure 4 - Alignment between the Alu primer used for the Alu-PCR technique and the LINE elements found in the bands of patients 2 and 5 and the flanking region without an $A l u$ element found in patients 3 and 9. 
binations and, consequently, to the formation of new rearrangements. This hypothesis is supported by Batzer and Deininger (2002) who stated that the high density of Alu elements in human DNA provides "hot spots" for homolog recombination and chromosomal translocation.

In the present work, genomic DNA from tumor tissue, surgical margins and blood from ten patients who underwent surgery for the removal of invasive ductal breast carcinoma was analyzed with $A l u-P C R$. The most frequently observed alteration in tumor tissue was the loss of fragments, with an average loss of one band for every 3.3 altered bands. This value was approximately twice that of the gain of new bands, on average 0.6 per patient for the same tissue. Surgical margins also showed alterations in the Alu-PCR profile, with frequencies of $0.5 \pm 0.97$ new bands and $0.5 \pm 0.85$ lost bands per patient This result may reflect the presence of tumor cells that are not detectable by the routine histopathological examination of surgical margins (Cesar et al., 2004, 2006; Hughes et al., 2006). Similarly, qualitative alterations in tumor tissue may be caused by the presence of normal stroma cells or leukocytes.

The sequences corresponding to the altered bands (1p36.23, 1q41, 11q14.3 and 13q14.2) belonged to regions associated with genomic instability and cancer. The loss of genetic material in chromosome $1 \mathrm{p}$ has been observed in many types of cancer, and is particularly frequent in breast, lung, endometrium and ovary cancer and in gliomas (Barbashina et al., 2005). The loss of heterozygosity suggested the presence of one (Ragnarsson et al., 1999) or several (Barbashina et al., 2005) tumor suppressor genes in this chromosomal arm.

Studies of different human neoplasias, including breast cancer, teratoma, astrocyte glioma, osteosarcoma, hepatocellular carcinoma and prostate cancer, have suggested the presence of a tumor suppressor gene in the long arm of chromosome 1 (Ding, 1992; Mertens, 1993; Murty et al., 1994; Li et al., 1995; Loupart et al., 1995; Berthon et al. 1998). In BLAST analysis, the sequence at 1q41 was located in an intronic region of the KCNK2 gene which coded for a member of the two-pore-domain background potassium channel protein family. Another member of this family, TASK3 or KCNK9, was also amplified and showed elevated expression in breast tumors. Elevated expression of TASK 3 in cell lines confers resistance to hypoxia and serum deprivation, suggesting an important physiological role for this gene in breast tumorigenesis (Mu et al., 2003). The loss of 500 bp by the KCNK2 gene deserves further studies since intron alterations can affect internal promoter or splicing sites, thereby changing gene expression.

A loss of heterozygosity in the $11 \mathrm{q} 14.3$ region has been observed in head and neck cancer and correlated with tumor grade (Glavac et al., 2003). In breast cancer cell lines studied by comparative genomic hybridization (CGH) and spectral karyotyping (SKY) the regions most commonly affected by LOH included 11q14-qter (Kytola et al., 2000).
The region 13q14 contains genes related to a variety of neoplasias, such as RB1, which however is located in a segment distant from the sequence analyzed. Some expressed sequence tags (DB448514, CD359283 and DB445670) have been mapped to the segment that comprises the sequenced clone, and the nearest gene is LCP1 of the plastin family of actin-bundling proteins. Foran et al. (2006) observed elevated expression of L-plastin associated with increased proliferation and invasion and loss of E-cadherin in a colorectal cancer cell line and suggested that this protein played an important role in metastasis.

Alu-PCR identified structural genetic alterations such as deletions and insertions and provided a profile of quantitative and qualitative changes in the samples studied here. These rearrangements were expected to be flanked by two Alu elements. The sequences showed three patterns in the five patients. The expected pattern was observed only in patient 10, with $A l u \mathrm{Sg} 1$ and $A l u \mathrm{Sg}$ flanking the insertion in tumor and marginal tissues. On the other hand, patients 2, 3, 5 and 9 had Alu at the 3' end but not at the 5' end. Patients 2 and 5 harbored the retroposon L1 (L1PA14 and L1ME1). L1 elements are long interspersed nuclear elements (LINES) associated with insertion mutations and chromosomal rearrangements that have been correlated with several human diseases, including breast cancer (Ostertag and Kazazian Jr, 2001). Patients 3 and 9 shared the same altered sequence with no transposable element at the 5 ' end. The amplification of these non-Alu sequences probably resulted from the lack of absolute specificity of the Alu primer at its 3' end. Non-specific annealing consistently occurred at the 5 ' end of the fragment, but we have no explanation for this selectivity.

Alu-PCR was originally designed to identify rearrangements mediated by Alus. However, as shown here, the Alu-primer amplified other sequences in addition to those flanked by Alus. Since L1 is a major source of non-specific genetic instability in humans the amplification also reveals genetic instability and do not compromise the efficiency of the technique. Our findings show that caution must be exercised when using this technique because of the risk of obtaining a spurious amplification, as observed for the 1 p36.23 region. Nevertheless, these spuriously amplified sequences are interesting because they may be involved in genetic rearrangements that include a gain or loss of fragments of DNA. Thus, Alu-PCR can be helpful as a preliminary strategy for screening regions of genomic instability involved in the initiation and progression of cancer and other diseases. The identification of unstable segments can function as potential biomarkers for the early detection of tumors and may be of prognostic use in monitoring disease progression.

\section{Acknowledgments}

This work was supported by CNPq fellowships granted to A.C. Fazza (108438/2004), C.M.A. Carareto 
(302421/2003-3) and E.H. Tajara (304886/2006-8). We thank anonymous reviewers for their critical comments.

\section{References}

Agata S, Dalla Palma M, Callegaro M, Scaini MC, Menin C, Ghiotto C, Nicoletto O, Zavagno G, Chieco-Bianchi L, D'Andrea E, et al. (2005) Large genomic deletions inactivate the BRCA2 gene in breast cancer families. J Med Genet 42:e64.

Barbashina V, Salazar P, Holland EC, Rosenlum MK and Ladanui M (2005) Allelic losses at 1p36 and 19q13 in gliomas: Correlation with histologic classification, definition of a $150 \mathrm{~kb}$ minimal deleted region on $1 \mathrm{p} 36$, and evaluation of CAMTA1 as candidate tumor suppressor gene. Clin Cancer Res 2:1119-1128.

Basik M, Stoler DL, Kontzoglou KC, Rodriguez-Bigas MA, Petrelli NJ and Anderson GR (1997) Genomic instability in sporadic colorectal cancer quantitated by inter-simple sequence repeat PCR analysis. Genes Chromosomes Cancer 18:19-29.

Batzer MA and Deininger PL (2002) Alu repeats and human genomic diversity. Nat Rev Genet 3:370-379.

Beckmann WM, Niederacher D, Schnürch HG, Gusterson BA and Bender HG (1997) Multistep carcinogenesis of breast cancer and tumor heterogeneity. J Mol Med 75:429-439.

Belogianni I, Apessos A, Mihalatos M, Razi E, Labropoulos S, Petounis A, Gaki V, Keramopoulos A, Pandis N, Kyriacou $\mathrm{K}$, et al. (2004) Characterization of a novel large deletion and single point mutations in the BRCA1 gene in a Greek cohort of families with suspected hereditary breast cancer. BMC Cancer 4:61.

Berthon P, Valeri A, Cohen-Akenine A, Drelon E, Paiss T, Wohr G, Latil A, Millasseau P, Mellah I, Cohen N, et al. (1998) Predisposing gene for early-onset prostate cancer, localized on chromosome 1q42-43. Am J Hum Genet 62:1416-1424.

Caetano-Anollés G and Bassam BJ (1993) DNA amplification fingerprinting using arbitrary oligonucleotide primers. Appl Biochem Biotechnol 42:189-200.

Ceron CR, Santos JR and Campos-Bicudo HEM (1992) The use of gelatin to dry cellophane wound slab gels in an embroidering hoop. Rev Bras Genet 15:201-203.

Cesar ACG, Borim AA, Caetano A, Cury PM and Silva AE (2004) Aneuploidies, deletion and overexpression of TP53 gene in intestinal metaplasia of patients without gastric cancer. Cancer Genet Cytogenet 153:127-132.

Cesar ACG, Calmon MF, Cury PM, Caetano A, Borim AA and Silva AE (2006) Genetic alterations in benign lesions: Chronic gastritis and gastric ulcer. World J Gastroenterol 12:625-629.

Chen JM, Stenson PD, Cooper DN and Ferec C (2005) A systematic analysis of LINE-1 endonuclease-dependent retrotranspositional events causing human genetic disease. Hum Genet 117:411-427.

Cordaux R, Hedges DJ, Herke SW and Batzer MA (2006) Estimating the retrotransposition rate of human Alu elements. Gene 373:138-144.

Deininger PL and Batzer MA (1999) Alu repeats and human disease. Mol Genet Metab 67:183-193.

Devilee P and Cornelisse CJ (1994) Somatic genetic changes in human breast cancer. Biochim Biophys Acta 1198:113-130.
Ding SF (1992) Different DNA changes in primary and recurrent hepatocellular carcinoma. Gut 33:1433-1435.

El-Ashry D and Lippmann ME (1994) Molecular biology of breast carcinoma. World J Surg 18:12-20.

Foran E, McWilliam P, Kelleher D, Croke DT and Long A (2006) The leukocyte protein L-plastin induces proliferation, invasion and loss of E-cadherin expression in colon cancer cells. Int J Cancer 118:2098-2104.

Furmaga WB, Ryan J, Coleman WB, Cole SR and Tsongalis GJ (2003) Alu profiling of primary and metastatic nonsmall cell lung cancer. Exp Mol Pathol 74:224-229.

Furmaga WB, Cole SR and Tsongalis GJ (2004) The use of AluPCR to distinguish between typical pulmonary carcinoids versus classic midgut carcinoids. Int J Oncol 24:223-226.

Glavac D, Volavsek M, Potocnik U, Ravnik-Glavac M and Gale N (2003) Low microsatellite instability and high loss of heterozygosity rates indicate dominant role of the suppressor pathway in squamous cell carcinoma of head and neck and loss of heterozygosity of 11q14.3 correlates with tumor grade. Cancer Genet Cytogenet 146:27-32.

Gonzalgo ML, Liang G, Spruck CH, Zingg JM, Rideout WM and Jones PA (1997) Identification and characterization of differentially methylated regions of genomic DNA by methylation-sensitive arbitrarily primed PCR. Cancer Res 57:594599.

Hall TA (1999) BioEdit: A user-friendly biological sequence alignment editor and analysis program for Windows 95/98/NT. Nucleic Acids Symp Ser 41:95-98.

Hughes S, Yoshimoto M, Beheshti B, Houlston RS, Squire JA and Evans A (2006) The use of whole genome amplification to study chromosomal changes in prostate cancer: Insights into genome-wide signature of preneoplasia associated with cancer progression. BMC Genomics 7:65.

Kenemans P, Verstraeten RA and Verheijen RHM (2004) Oncogenic pathways in hereditary and sporadic breast cancer. Maturitas 49:34-43.

Kytola S, Rummukainen J, Nordgren A, Karhu A, Farnebo F, Isola $\mathrm{J}$ and Larsson C (2000) Chromosomal alterations in 15 breast cancer cell lines by comparative genomic hybridization and spectral karyotyping. Genes Chromosomes Cancer 28:308-317.

Li YS, Ramsay DA, Fan YS, Armstrong RF and Del Maestro RF (1995) Cytogenetic evidence that a tumor suppressor gene in the long arm of chromosome 1 contributes to glioma growth. Cancer Genet Cytogenet 84:46-50.

Loupart ML, Armour J, Walker R, Adams S, Brammar W and Varley J (1995) Allelic imbalance on chromosome 1 in human breast cancer. I. Minisatellite and RFLP analysis. Genes Chromosomes Cancer 12:16-23.

Mertens F (1993) Cytogenetic findings in 33 osteosarcomas. Int J Cancer 55:44-50.

Montagna M, Palma MD, Menin C, Agata S, De Nicolo A, Chieco-Bianchi L and D'Andrea E (2003) Genomic rearrangements account for more than one-third of the BRCA1 mutations in northern Italian breast/ovarian cancer families. Hum Mol Genet 12:1055-1061.

Mu D, Chen L, Zhang X, See LH, Koch CM, Yen C, Tong JJ, Spiegel L, Nguyen KC, Servoss A, et al. (2003) Genomic amplification and oncogenic properties of the KCNK9 potassium channel gene. Cancer Cell 3:297-302. 
Murty VV, Li RG, Mathew S, Reuter VE, Bronson DL, Bosl GJ and Chaganti RS (1994) Replication error-type genetic instability at 1q42-43 in human male germ cell tumors. Cancer Res 54:3983-3985.

Ng SK and Xue H (2006) Alu-associated enhancement of single nucleotide polymorphisms in the human genome. Gene 368:110-116.

Ostertag EM and Kazazian Jr HH (2001) Biology of mammalian L1 retrotransposons. Annu Rev Genet 35:501-538.

Peinado MA, Malkhosyan S, Velazquez A and Perucho M (1992) Isolation and characterization of allelic losses and gains in colorectal tumors by arbitrarily primed polymerase chain reaction. Proc Natl Acad Sci USA 89:10065-10069.

Presneau N, Laplace-Marieze V, Sylvain V, Lortholary A, Hardouin A, Bernard-Gallon D and Bignon YJ (1998) New mechanism of BRCA-1 mutation by deletion/insertion at the same nucleotide position in three unrelated French breast/ovarian cancer families. Hum Genet 103:334-339.

Ragnarsson G, Eiriksdottir G, Johannsdottir JT, Jonasson JG, Egilsson V and Ingvarsson S (1999) Loss of heterozygosity at chromosome 1p in different solid human tumours: Association with survival. Br J Cancer 79:1468-1474.

Rowold DL and Herrera RJ (2000) Alu elements and the human genome. Genetica 108:57-72.

Sambrook J, Fritsch EF and Maniatis T (1989) Molecular Cloning. A Laboratory Manual. 2nd edition. Cold Spring Harbor Laboratory Press, New York.

Stenger JE, Lobachev KS, Gordenin D, Darden TA, Jurka J and Resnick MA (2001) Biased distribution of inverted and di- rect Alus in the human genome, implications for insertion, exclusion, and genome instability. Genome 11:12-27.

Strout MP, Marcucci G, Bloomfield CD and Caligiuri MA (1998) The partial tandem duplication off $A L L-1$ (MLL) is consistently generated by Alu-mediated homologous recombination in acute myeloid leukemia. Proc Natl Acad Sci USA 95:2390-2395.

Suminaga R, Takeshima Y, Yasuda K, Shiga N, Nakamura H and Matsuo M (2000) Non-homologous recombination between Alu na LINE-1 repeats caused a $430-\mathrm{kb}$ deletion in the dystrophin gene: A novel source of genomic instability. J Hum Genet 45:331-336.

Tsongalis G, Coleman W, Esch G, Smith G and Kaufman D (1993) Identification of human DNA in complex biological samples using the Alu polymerase chain reaction. J Forensic Sci 38:961-967.

Weichenrieder O, Stehlin C, Kapp U, Birse DE, Timmins PA, Strub K and Cusack S (2001) Hierarchical assembly of the Alu domain of the mammalian signal recognition particle. RNA 7:731-740.

\section{Internet Resources}

Instituto Nacional do Câncer (INCA), http://www.inca.gov.br/.

Basic Local Alignment Search Tool (BLAST), http://www.ncbi.nlm.nih.gov/BLAST/.

BLAT, http://genome.ucsc.edu/cgi-bin/hgBlat?command = start.

Editor: Angela M. Vianna-Morgante

License information: This is an open-access article distributed under the terms of the Creative Commons Attribution License, which permits unrestricted use, distribution, and reproduction in any medium, provided the original work is properly cited. 